\title{
Hidden Hunger, A Global health problem
}

\section{Khan MK ${ }^{1}$}

People of developing \& underdeveloped countries often does not give much attention to healthy \& nutritious food. It is mostly because of their ignorance \& poverty. That's why they often suffer from malnutrition \& chronic vitamins \& minerals deficiency. Specially they suffer from Iron, vitamin A, iodine \& zinc deficiency. So anemia, goiter, increase chance of infection, mental retardation, stunting are predominantly common in these countries.

Hidden hunger is a lack of vitamins and minerals. Hidden hunger occurs when the quality of food, people eat does not meet their nutrient requirements, so the food is deficient in micronutrients such as the vitamins and minerals that they need for their growth and development. Two billion people suffer from vitamin and mineral deficiencies. Women and children in families with low-income often don't get enough vitamin $A$, iodine and iron, and sometimes other essential nutrients. This limits their growth, development, health and working capacity. Ensuring people get vitamins, minerals and essential nutrients will help to prevent malnutrition. ${ }^{1}$

"The Hidden hunger due to micronutrient deficiency does not produce hunger as we know it. You might not feel it in the belly, but it strikes at the core of your health \& vitality." -Kul C Gautam, former deputy executive director of UNICEF.

The cost of hidden hunger is huge in our lives-more than 2 billion people worldwide suffer from hidden hunger, almost twice the number of those suffering from hunger of food. Approximately $7 \%$ of the annual global disease burden. $2 \%-3 \%$ loss of GDP. Almost $9 \%$ of global childhood disability adjusted life years (DALYs). More than 10\% losses of lifetime individual earnings. ${ }^{2}$

Deficiencies in essential vitamins and minerals-also termed hidden hunger-are pervasive and hold negative consequences for the cognitive and physical development of children. ${ }^{3}$

A study conducted in Nepal to find out the cause, consequences \& solution regarding micronutrient deficiency. They found the general people are not aware of food rich in micronutrients \& they are also not aware of consequences of micronutrient deficiencies. ${ }^{4}$

Hidden hunger is a preventable condition. But one of the World's greatest challenges is to secure sufficient and healthy food for all, and to do so in an environmentally sustainable manner. Through a systematic holistic approach can prevent this condition. $^{5}$

Many indigenous foods are found to be rich sources of micronutrients like calcium, iron, vitamin $A$ and folate. Maximizing utilization of indigenous foods can be an important and sustainable dietary diversification strategy for addressing hidden hunger. ${ }^{6}$

1. Professor Dr. Mahbub-Ul-Karim Khan

Professor, Department of Paediatrics and Director

Community Based Medical College Hospital, Bangladesh.

${ }^{*}$ Address of correspondence Email- mmukkhan@gmail.com Mobile: 0088-01711350724 
To change this scenario increase awareness \& attitudinal change, regarding healthy food is mandatory. First 1000 days (conception to two years) feeding for our children is very important. We have to give due attention to the food of our pregnant \& lactating mother \& simultaneously have to give emphasis on infant \& young child feeding. As we know better food, better nutrition, better health \& better future.

\section{References}

1. http://www.who.int/nutrition/topics/W HO_FAO_ICN2_videos_hiddenhung er/en/

2. Muthayya $\mathrm{S}$, Rah $\mathrm{JH}$, Sugimoto JD, Roos FF, Kraemer K, Black RE (2013) The Global Hidden Hunger Indices and Maps: An Advocacy Tool for Action. PLoSONE8(6):e67860.doi:10.1371/j ournal.pone.0067860

3. Ruel-Bergeron JC1, Stevens GA2, Sugimoto JD3, Roos FF4, Ezzati M5, Black RE1, Kraemer K, Global Update and Trends of Hidden Hunger, 1995-2011: The Hidden Hunger Index. PLOS One. 2015 Dec 16;10(12):e0143497.doi:10.1371/jou rnal.pone. 0143497. eCollection 2015.

4. Bhandari S1, Banjara MR2, Micronutrients Deficiency, a Hidden Hunger in Nepal: Prevalence, Causes, Consequences, and Solutions. IntSch Res Notices. 2015 Jan15;2015:276469.doi:10.1155/201 5/276469. eCollection 2015.
5. Burchi F1, Fanzo J, Frison E. The role of food and nutrition system approaches in tackling hidden hunger. Int $\mathrm{J}$ Environ Res Public Health. 2011 Feb;8(2):358-73. doi: 10.3390/ijerph8020358. Epub 2011 Jan 31.

6. Ghosh-Jerath S1, Singh A2, Magsumbol MS3, Kamboj P1, Goldberg G4.Exploring the Potential of Indigenous Foods to Address Hidden Hunger: Nutritive Value of Indigenous Foods of Santhal Tribal Community of Jharkhand, India. J Hunger Environ Nutr. 2016 Oct 1;11(4):548-568. Epub 2016 May 5. 